\title{
NIGERIAN NURSES AND MIDWIVES UNEMPLOYMENT SURVEY
}

\author{
RN, E., 1 凹 , RN, G. N. ${ }^{2}$ \\ 1,2 University Graduates of Nursing Science Association (UGONSA)
}

DOI: https://doi.org/10.29121/granthaalayah.v8.i6.2020.340

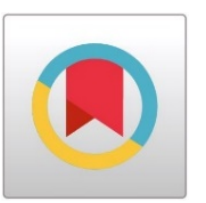

Article Type: Research Article

Article Citation: RN, E., and RN, G. N.. (2020). NIGERIAN NURSES AND MIDWIVES UNEMPLOYMENT

SURVEY. International Journal of Research -GRANTHAALAYAH, 8(6), 92-101. https://doi.org/10.29121/granthaa layah.v8.i6.2020.340

Received Date: 03 May 2020

Accepted Date: 22 June 2020

Keywords:

Unemployment

Nursing

Midwifery

Opportunity

Remuneration

Facilities

\section{ABSTRACT}

Background: The quacking controversy that trailed the Nursing \& Midwifery Council of Nigeria's (N\&MCN) release of a "License Community Nurse (LCN)" circular (Ref No. N\&MCN/SG/RO/CIR/24/VOL.4/152 dated March 3, 2020) which conveyed the intention of the council to lower the existing standard of nursing education for the LCN programme that will take secondary school leavers at least a credit in English and Biology to be admitted into and two years to complete, and inter alia blamed the crude situation and abysmal performance of the Nigerian Primary Healthcare (PHC) system in the community settings on mass migration of Nurses \& Midwives to urban areas and to other countries prompted UGONSA to initiate this survey to empirically determine whether there are indeed a shortage of Nurses \& Midwives to fill the manpower need of the Nigerian PHC system in the community settings or not, or whether the shortage is as a result of the deliberate age-long policy of attrition and displacement of Nurses \& Midwives from the PHC system in the community settings and their replacement with Community Health Extension Workers (CHEWs) [who do not have nursing education, training, skills or the ethical leaning to be responsible and accountable for nursing \& midwifery services] by the National Primary Healthcare Development Agency (NPHCDA).

Objective: The main aim of the study was to determine if there is a shortage of nurses that could fill the nursing needs of the PHC system in the community settings. The study also sought to compile the list of unemployed and underemployed Nurses \& Midwives and to find out if unemployed Nurses \& Midwives are willing to work in the community settings if the opportunity to serve the PHC system in the community setting is offered to them by the NPHCDA. The study further sought to determine the ratio of unemployed Nurses \& Midwives in relation to the possible number of graduates that can be licensed by the N\&MCN in a session.

Methods: Using Google forms an online compilation was carried out from March 7 to April 08, 2020, in a descriptive survey of unemployed Nurses \& Midwives that could be reached online within the timeline. Names, Phone numbers, State of Residence, Year of Graduation, Qualification(s), and how long they have remained unemployed after graduation were compiled. In addition, two questions were asked about the objective of the study. Analysis of data was done via Google forms statistical tools.

(C) 2020 The Author(s). This is an open access article distributed under the terms of the Creative Commons Attribution License, which permits unrestricted use, distribution, and reproduction in any medium, provided the original author and source are credited. 


$$
\text { RN, E., and RN, G. N. }
$$

Results: A total of 3317 unemployed Nurses \& Midwives responded to the survey. Among these unemployed Nurses \& Midwives - 38\% holds RN only, 19\% holds both RN \& RM, 15.4\% holds RM only, while 27.6\% holds BNSc plus another qualification. For the year they have remained unemployed after graduation $57.1 \%$ have spent $0-2$ years, 29.9\% have been unemployed for 3-5 years, 7\% have been unemployed for $6-8$ years and $6.1 \%$ have been unemployed for more than 8 years. To the question, "Do you think there is a shortage of Nurses and Midwives in Nigeria?" - $47.5 \%$ said yes, $43.5 \%$ said no whereas 9\% were undecided (said maybe). Furthermore, the result showed that while $95 \%$ of the unemployed Nurses \& Midwives are willing to work in the rural community settings, $1 \%$ was not willing to work in the rural community settings and $4 \%$ were undecided (.i.e. said maybe) on whether they will work in the rural community settings or not. The result also revealed that the 3317 unemployed Nurses \& Midwives captured in the survey represents graduates of 66 Nursing \& Midwifery schools per session out of a total of 162 schools that are currently accredited by the N\&MCN. This represents $41 \%$ of the possible number of graduates that can be turned out of the accredited Nursing \& Midwifery Schools (excluding Post-basic schools) in a session.

Conclusion: Despite the reported migration of Nurses to urban areas and other countries, at least $41 \%$ of Nigerian Nurses \& Midwives produced in a session remain unemployed and 95\% of them are willing to work in the rural community settings if given the opportunity. These unemployed Nurses \& Midwives can bridge the Nursing \& Midwifery manpower needs in the Primary Healthcare System should the NPHCDA engage their services with a commensurate or higher payment to what their employed counterparts receive in Federal Government-owned establishments and hospitals. There is no current shortage of Nurses that necessitates the lowering of the existing standard of nursing education. Nurses \& Midwives are not responsible for the design, implementation, and delivery of healthcare services at the PHC level and therefore are not culpable for the deplorable condition and abysmal performance of the Nigerian PHC System.

\section{INTRODUCTION}

\subsection{BACKGROUND}

The Nursing \& Midwifery Council of Nigeria stirred a quaking controversy in the Nursing community when on March 3, 2020, it released a circular Ref No: N\&MCN/SG/RO/CIR/24/VOL.4/152 which conveyed its intent to lower the existing standard of nursing education via the introduction of a 2- years program for a lower cadre of Nurses christened "Licensed Community Nurse (LCN)" with having a poor O'level result (.i.e. at least a credit in English and Biology) being the principal admission requirement. The circular titled, "INTRODUCTION OF COMMUNITY NURSING PROGRAMME AS A MODALITIES FOR STRENGTHENING NURSING HUMAN RESOURCES AT THE PRIMARY HEALTHCARE LEVEL AND REDUCTION OF MATERNAL AND INFANT MORTALITY IN NIGERIA" sounded that currently there is a great demand for nursing care to be assessable to children, adolescents, adults, older people, vulnerable groups, victims of crime and disasters, and internally displaced persons, in their communities and settlements [which indeed is the primary reason for the existence of the Primary Healthcare (PHC) system]. The council in the circular attributed its reason for embarking on the voyage of breeding this lower cadre of nurses to "gross shortage of Nursing manpower at the community level occasioned by the mass migration of Nurses to urban areas and other countries with a resultant weakening of the Primary Health System and poor access to healthcare by rural dwellers in the country". The council went further to cast the health-related Sustainable Development Goals (SDGs) and Universal Health Coverage (UHC) as unmet in the country owing to shortage of Nurses to paddle the boat of care in the rural community settings hence the need to lower the existing standard of nursing education and create the lower LCN cadre to fill the gap (N\&MCN, 2020a). Put in another way, the N\&MCN acknowledged that the Primary Healthcare system of Nigeria is in a total mess but that Nurses should be blamed for this mess for their migration to urban areas and other countries.

While many nurses and nursing groups agreed with the council that the Primary Healthcare (PHC) system is in a degrading rot they vehemently disagreed that the appalling state of the system was caused by a shortage of nursing manpower to drive the system and cautioned the council not to jeopardize the existing standard of nursing education or the quality of nursing manpower with the planned lower cadre nursing program which prospectively targets the weakest secondary school graduates (.i.e. those with at least a credit in English and Biology) for admission into nursing (N\&MCN, 2020a). Many believed that there is no shortage of nursing manpower in Nigeria citing the 
mammoth crowd of nurses that apply for recruitment whenever any government-owned hospital floats advert for recruitment of nurses as the basis for their stand. They argued that if similar payment for the nursing \& midwifery job opportunities availed for Nurses \& Midwives in Federal Government-owned hospitals or establishments that do attract a mammoth crowd of unemployed Nurses \& Midwives, whenever job adverts are made in Federal Government-owned hospitals or establishments, should also be made available at the rural community settings via the Primary Healthcare (PHC) system, many Nurses \& Midwives would troupe into the communities for employment.

In the opinion of many nurses, the National Primary Healthcare Development Agency (NPHCDA) was rather to be blamed for failing to engage the services of the many unemployed Nurses \& Midwives who are roaming the streets in search of scarce nursing \& midwifery jobs. Nursing is the heartbeat and cornerstone of the PHC system globally but in Nigeria, the NPHCDA has since its creation in the year 1992 removed nursing as the cornerstone and rather made the outsourcing of nursing \& midwifery services to the Community Health Extension Workers (CHEWs) its driving policy. The CHEWs were created as a smokescreen for waging an organized war of attrition on Nurses \& Midwives in the PHC system by the medical doctors who hold sway at the Federal Ministry of Health right from the inception of the NPHCDA principally to dislodge nursing from holding any position of influence in the system that may attract respect for the profession from the rural community dwellers and the general public. In bowing to pressure from his medical colleagues to create the CHEWs as a tool to wither the influence and contribution of Nurses \& Midwives in the health system, Prof. Olikoye Ransome-Kuti (the Minister of Health under whose tenure the NPHCDA was established in the year 1992) had falsely alleged that Nurses \& Midwives had rejected taking up nursing \& midwifery services in the rural community settings even when nobody had mobilized them for such in the then newly established PHC services and thus he sinisterly created the CHEWs as a replacement for Nurses \& Midwives in the PHC system using this false allegation as a red herring. Professor Ransome-Kuti had regretted this action when he left office after seeing the health indices of the country worsen as a result of this faulty policy he had promoted in the health system. As he admitted when he stood down as the Minister of Health, "my only regret as I leave the ministry is that I have not been able to mobilize all health workers behind the medical system. Most health workers are only interested in how to maintain their position in the hospital system." (Raufu, 2003). Thus, Prof. RansomeKuti, like other Ministers of Health (MOH) who are medical doctors, have had the golden opportunity of mobilizing all the health workers behind the

Nigerian health system but chose to be divisive \& chauvinistic and more interested in assigning and maintaining positions for their medical colleagues. The parsimonious regret and acknowledgment of Prof. Ransome-Kuti that he had deliberately ostracized and replaced Nurses \& Midwives with the CHEWs instead of mobilizing them behind the health system because he chose to appease his medical colleagues who are more interested in occupying and being in charge of positions over deploying skilled nursing \& midwifery services in delivering qualitative healthcare to the people in the rural community settings was rather playing to the gallery as nothing has been done till date to correct the anomaly.

Nigeria thus sadly represents an anomalous situation where the central coordinating roles of nursing have been ceded to the CHEWs at the detriment of quality client care. This has made the health indices of the country negatively nosedive and has catapulted the country's health system to an exalted seat among the global worse health systems despite having a PHC system that has engulfed millions of dollars over the years. NPHCDA has over the years relegated Nurses \& Midwives to the background and egregiously made the CHEWs the cornerstone of nursing \& midwifery services of the PHC system in the rural community settings despite that the CHEWs do not have nursing education, training, skills or the ethical leaning to be responsible and accountable for nursing \& midwifery services. The situation is so bizarre that the CHEWs are made to even assume leadership over nursing in a few situations where Nurses \& Midwives are allowed access to the system that has been deliberately gated against them. In other words, the CHEWs are in charge of and administer nursing \& midwifery services in the Nigerian PHC system despite not being qualified Nurses \& Midwives or having the competency and the capacity to do so and they are bizarrely in charge of nursing \& midwifery services in the rural community settings even when qualified, capable and competent Nurses \& Midwives are available.

The deliberate displacement of Nurses \& Midwives from their jobs with the CHEWs is glaringly evident in the NPHCDA dedicating one out of its nine departments to the services of the CHEWs (.i.e. the Department of Community Health Services) whereas no department of Nursing services exist at the agency to coordinate and oversee nursing \& midwifery services as is the norm in climes where nursing is playing its normal central coordinating roles in the PHC system. Nursing which ordinarily should be the bedrock, backbone, heartbeat and the cornerstone of the system is alas the rejected central pillar in the Nigerian PHC system.

International Journal of Research -GRANTHAALAYAH 
RN, E., and RN, G. N.

Nursing is nowhere near the system design or leadership of the PHC, which are mainly occupied by physicians, few administrators, and the CHEWs to the exclusion of Nurses \& Midwives, despite that the core of the services rendered by the system is nursing \& midwifery services. Not having a department of Nursing Services at the NPHCDA portends that nurses have no frontline roles in the PHC system of the country and therefore are not responsible for the mess in the system. This is especially as the model of healthcare services delivered in the community settings under the PHC system in Nigeria is CHEW-driven, CHEW-centred, and, CHEW-headed rather than nursing driven, nursing-centered, or nursing- headed. To dish out CHEW services in place of nursing \& midwifery services and expect to get the results for nursing \& midwifery services is foolhardy. To blame nursing for the failure of the PHC system whose nursing \& midwifery services are handled by the CHEWs (who have no nursing \& midwifery background or preparation) at the expense of Registered Nurses \& Midwives is preposterous. The case of the PHC system in ceding nursing \& midwifery services to the CHEWs in the rural community settings is akin to ceding engineering works to carpenters and still expecting to get a good result. The Nigerian PHC system is arguably in a total mess because people that do not have nursing \& midwifery background were mobilized and made the centrifuge for nursing \& midwifery services over the years. Therefore, the failure of the PHC system should be squarely blamed on the NPHCDA for making the system more of an obtuse political system that is interested in maintaining positions, as confessed by Prof. Ransome-Kuti, than a healthcare delivery system that mobilizes appropriate personnel for qualitative care delivery. Until the square peg is put in the square hole the PHC system of Nigeria will remain a sham.

A review of the contemporary health indices of the country especially those of the rural community settings which the NPHCDA was established to turn around are imperative in the subject matter. The National Primary Healthcare Development Agency (NPHCDA) was established in the year 1992 with a mandate to make healthcare delivery in the community settings robust to achieve universal health coverage for Nigerians and stem the tide of high maternal and child mortality \& morbidity in Nigeria. However, the worsening contemporary health indices of the country show that the agency is very far from achieving this mandate and needs an urgent systemic rejig and a comprehensive overhaul. Nigeria has consistently remained among the most dangerous place for a woman to be pregnant or a child to be born in the world courtesy of failure of the PHC system to address the health needs of the rural communities (Odetola, 2015; Odogwu, 2018). Ononokpono and Odimegwu (2014) lamented that although there has been a decline in maternal deaths globally, the maternal mortality rate in Nigeria is still unacceptably high as pregnancy \& delivery is still very well associated with suffering, morbidity, and death especially in rural community settings. In Nigeria, it has been reported that an estimated 2,300 children under the age of five and 145 women of childbearing age die every single day, making the country to account for the second-largest number of maternal and child deaths in the world (United Nations Children's Emergency Fund [UNICEF], 2015; Ifijeh, 2016). CIA World Factbook (2018) equally reported that the maternal mortality rate resulting from obstetrics episodes in Nigeria is estimated to be 814 deaths/100,000 live births, which is about four times higher than the global average of 216 deaths per 100,000 live births (WHO, 2018), making Nigeria that accounts for 2.4\% of the global population to carry $14 \%$ of the global burden of maternal mortality (USAID, 2016). The high maternal \& child mortality rate in the community settings has been attributed to inadequate utilization of skilled manpower to provide maternal \& child healthcare services (Ononokpono and Odimegwu, 2014). Delivery in a health facility, staffed with skilled healthcare providers such as Nurses \& Midwives is associated with lower maternal \& child mortality and morbidity rates compared with delivery at centers that lack skilled Nursing \& Midwifery services (Odetola, 2015; Ifijeh, 2016; WHO, 2018). The National Primary Health Care Development Agency (Nigeria) [NPHCDA] itself in its report confirmed that the Nigerian Primary Healthcare (PHC) system grossly lacks the services of skilled care providers such as Nurses \& Midwives and attributed such to be responsible for the high incidence of maternal \& child mortality and morbidity witnessed in the country. NPHCDA (2016) had reported that of $61 \%$ of pregnant women receiving care by a skilled provider in Nigeria, only $38 \%$ of births are attended to by skilled birth providers while only $36 \%$ deliver in health facilities with skilled providers, which mostly are located in urban settings. This report by the NPHCDA itself shows that it knows that its age-long practice of relegating skilled nursing \& midwifery services to the background with the CHEW services in the rural community settings is the bane of the PHC system but elected to continue to perpetuate such on the chancel of politics. The poor state the PHC system has been heralded into over the years was even corroborated by an earlier report from the 2008 Nigeria Demographic and Health Survey (NDHS) which stated that only $38 \%$ of pregnant Nigerian women deliver in a health facility with skilled providers which are mostly located in the urban areas (National Population Commission, ICF Macro, 2009). WHO (2011) capped it with its report that Nigeria has had a very poor record regarding maternal and child health outcomes as an estimated 53,000 women and 250,000 newborns die annually mostly as a result of preventable causes. This figure is even 
worsening as the years go by (Odogwu, 2018). There has been an air of suspicion among Nurses that the Midwifery Service Scheme (MSS) established in the year 2009 for the deployment of qualified, unemployed or retired midwives, to selected primary health care facilities in rural communities to facilitate an increase in the coverage of Skilled Birth Providers (SBP) to reduce maternal, newborn and child mortality was allowed by the NPHCDA to die off out of lack of funding because some highly placed individuals in the agency were at odd as per why the scheme should engage the services of midwives and not that of the CHEWs. The introduction of the now-defunct MSS would not have even arisen or been necessary in the first place had Nurses \& Midwives been engaged and deployed for the services of the PHC system in the rural community settings over the years.

At the present moment, the woes of those in the community setting are further compounded by different factors that fuelled the surge of internally displaced persons (IDPs) within the past decade such as terrorism, herdsman crisis, communal clashes, and natural disasters. Having a litany of IDPs camps in the face of non-functional PHC system with crude facilities dotted with CHEWs' services supplanting the much needed skilled nursing \& midwifery services portend that children, women, adolescents, adults, older people, vulnerable groups, victims of crime and disasters, and internally displaced persons have been abandoned to their fate in the community settings.

From the foregoing, it is convenient to infer that the Sustainable Development Goal (SDG) 3, which borders on good health and well-being, will perpetually remain a mirage in Nigeria rural communities as long as the status quo of relegating skilled nursing \& midwifery services to the background persists in our PHC system. Since the N\&MCN blamed the failure of the PHC system on the shortage of nurses and on the other hand, many Nurses and nursing groups denounced and disagreed with this claim by the council and rather blamed the mess on the NPHCDA for supplanting nursing \& midwifery services with CHEW services, it is thus imperative to determine empirically whether there is indeed a shortage of nurses or not and whether unemployed nurses \& midwives are willing to work in the rural community setting should the opportunity be offered to them.

\section{METHODS}

A compilation of unemployed Nurses \& Midwives was done online via various social media platforms of the Nigerian nursing community using Google forms. Data collection was done from March 7 to April 08, 2020, compiling unemployed Nurses \& Midwives that could be reached online within the timeline. The descriptive survey sought to have a compiled list of unemployed Nurses \& Midwives at the time of the study and as well elicit their responses on the notion of a shortage of nurses and their willingness to work in the rural community setting if offered the opportunity. The following socio- demographic data were collected: Names, Phone numbers, State of Residence, Year of Graduation, Qualification(s), and how long they have remained unemployed after graduation. In addition, two questions were asked in line with the objective of the study with options for selecting "Yes, No or Maybe". The two questions are: (1) Do you think there is a shortage of Nurses and Midwives in Nigeria? (2) With a good remuneration, good working condition and good facilities, will you be willing to work in the rural community setting? Data collected were analyzed using Google forms' statistical tools.

\section{RESULTS}

A total of 3317 unemployed Nurses \& Midwives responded to the survey. Among these unemployed Nurses \& Midwives - 38\% holds RN only, 19\% holds both RN \& RM, 15.4\% holds RM only, while $27.6 \%$ holds BNSc plus another qualification. For the year they have remained unemployed after graduation $57.1 \%$ have spent $0-2$ years, 29.9\% have been unemployed for 3-5 years, 7\% have been unemployed for $6-8$ years and $6.1 \%$ have been unemployed for more than 8 years. To the question, "Do you think there is a shortage of Nurses and Midwives in Nigeria?" - 47.5\% said yes, 43.5\% said no whereas 9\% were undecided (said maybe). Furthermore, the result showed that while $95 \%$ of the unemployed Nurses \& Midwives are willing to work in the rural community settings, $1 \%$ was not willing to work in the rural community setting and $4 \%$ were undecided (i.e. said maybe) on whether they will work in the rural community setting or not. The result also revealed that the 3317 unemployed Nurses \& Midwives captured in the survey represents graduates of 66 Nursing \& Midwifery schools per session out of a total of 162 schools that are currently accredited by the N\&MCN as stated on the council website [.i.e. 85 Schools of Nursing, 42 Schools of Basic Midwifery, 27 Departments of Nursing and 8 schools of Community Midwifery program] (N\&MCN, 2020b). This was derived from the fact that the Nursing \& Midwifery Council of Nigeria (N\&MCN) allots 50 


$$
\text { RN, E., and RN, G. N. }
$$

indexing slots per school per session. This infers that the existing schools have the potential to graduate 8100 Nurses \& Midwives per session should they all present 50 candidates each for council exams with all the candidates passing the exams. Therefore the unemployed Nurses \& Midwives represents at least $41 \%$ of all graduates expected to be turned out by all the Nursing \& Midwifery Schools combined (excluding Post-basic schools) in a session assuming that all the schools index and present 50 candidates each for the Nursing \& Midwifery qualifying exams and that all candidates presented for the exams pass them.

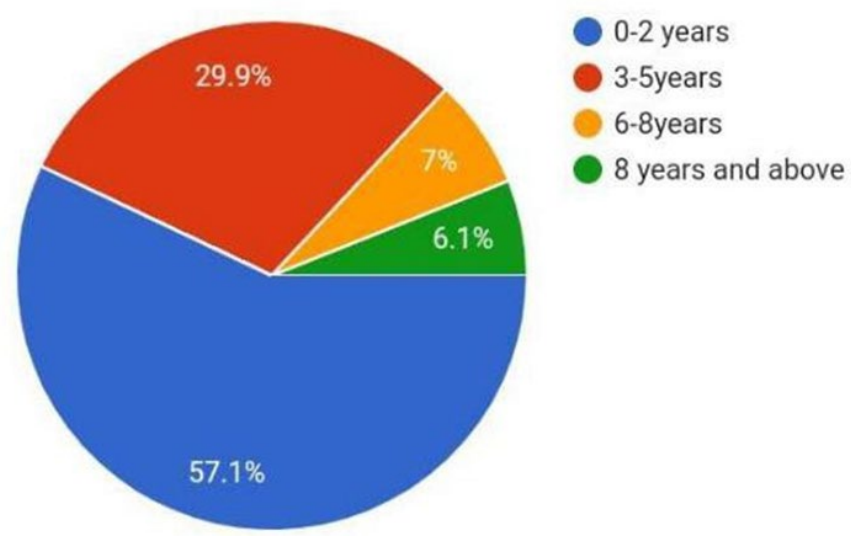

How long have you been unemployed?

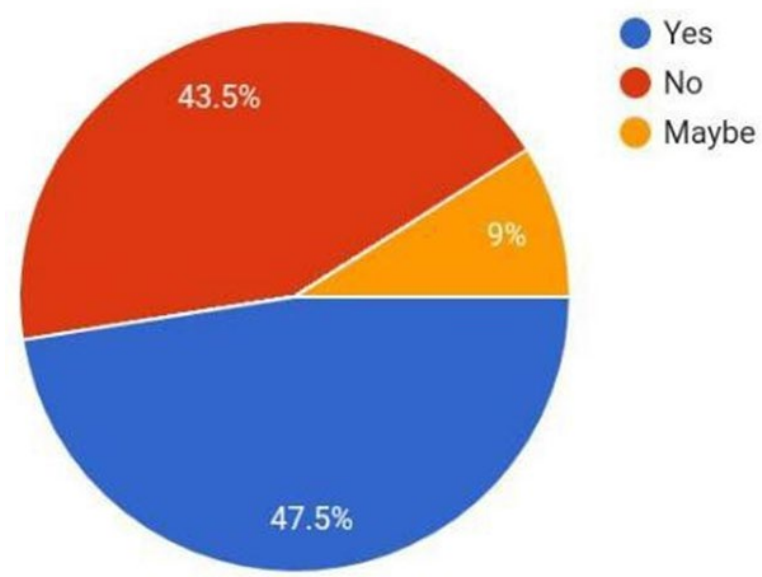

Do you think there is a shortage of Nurses \& Midwives in Nigeria?

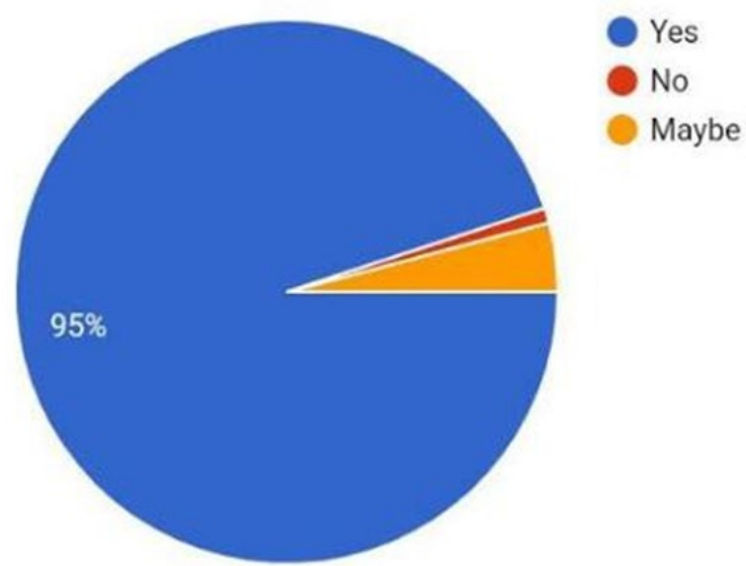

With good remuneration, good working condition, and facilities will you be willing to work in the rural community setting? 

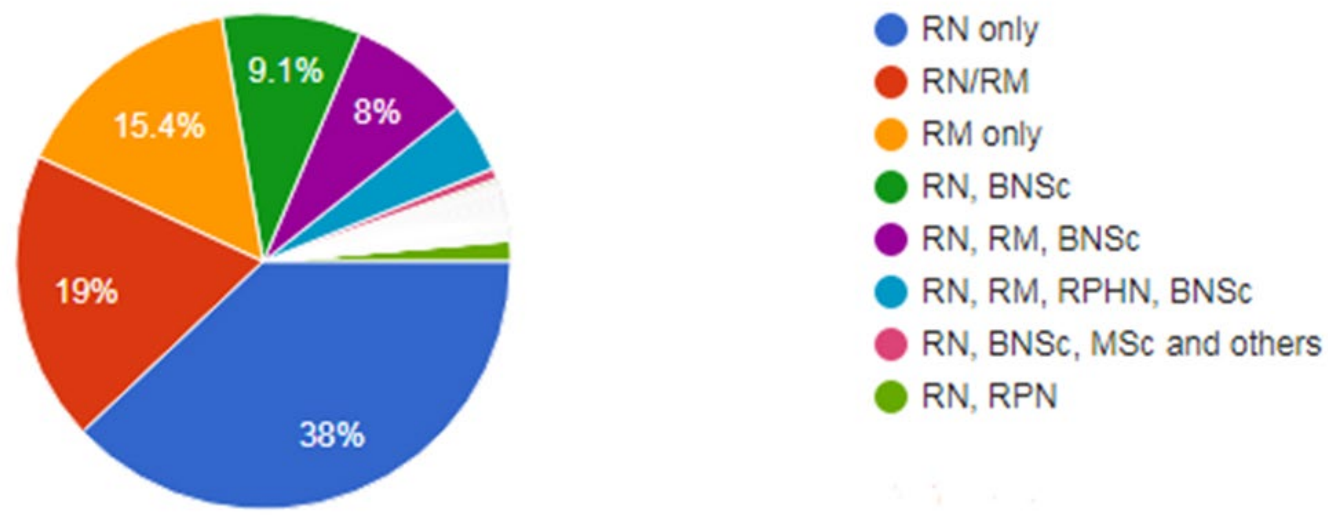

Qualifications

\section{DISCUSSION}

The findings that 7\% of the unemployed Nurses \& Midwives have been unemployed for $6-8$ years and that $6.1 \%$ have been unemployed for more than 8 years is striking for a country whose PHC system was said to be having a gross shortage of nursing manpower. The results showed that available Nurses \& Midwives are in excess and unemployed for many years after graduation and not in shortage as stated by the N\&MCN. The finding that many Nurses \& Midwives who are willing to work in the rural community settings remain unemployed for even up to more than 6 to 8 years after graduation strongly disagreed with the position of the Nursing and Midwifery Council of Nigeria in the circular, (Ref No. N\&MCN/SG/RO/CIR/24/VOL.4/152 dated March 3, 2020), wherein it posited that the quest to fill in the gap of 'a great shortage of nursing manpower' to be engaged for delivery of care in the rural community settings had necessitated its move to lower the existing standard of nursing education to produce a lower cadre of Nurses in the form of Licensed Community Nurses (LCN) who would be admitted into nursing for a twoyear program with a poor O'level result of at least a credit in English and Biology. The study showed that there is no Nurses' shortage gap for the N\&MCN to fill with the proposed LCN since a good number of the available Registered Nurses \& Midwives are still unemployed years after graduation. Again, the findings that among the unemployed Nurses \& Midwives are nurses with dual or multiple qualifications indicates that these unemployed Nurses \& Midwives have specialized skills to bring on board in the community settings to improve health and well-being of the rural dwellers should their services be engaged by the NPHCDA to serve the PHC system in the community settings.

The findings that $95 \%$ of the unemployed Nurses \& Midwives are willing to work in the rural community settings if offered the opportunity confirms that it was not a shortage of nurses that buoys their little or none visibility at the rural community settings but not being offered the opportunity to work in the PHC system at the community settings by the NPHCDA. Not finding any opportunity at the community level they switch to any available option such as selfemployment, abandoning nursing for other businesses or vocations and turning to urban areas or other countries for employment opportunities. The study, therefore, contradicts the postulation of the N\&MCN that the inability of the people in the rural community setting to assess the much-needed nursing services is due to the shortage of nurses occasioned by the mass migration of nurses to urban areas and other countries.

The findings that at least $41 \%$ of the possible numbers of Nurses \& Midwives that can be licensed by the N\&MCN in a session are unemployed shows that unemployment is a serious issue among Nigerian Nurses \& Midwives. This unemployed leftover from the annual turnover of Nurses \& Midwives in Nigeria can bridge the nursing manpower needs in the rural community settings if engaged and deployed to serve the system from year to year. From the study, it is now comprehensive that while other countries make deliberate effort to build up their nursing manpower at the grassroots and ensure universal health coverage across communities by adopting extreme staffing measures for skilled healthcare providers such as engaging the services of foreign nurses, in Nigeria, the reverse is the case. The Nigerian Primary Healthcare (PHC) system has perennially adopted an uncouth extreme measure of ostracizing Nurses \& Midwives from the system such that the skilled nursing manpower that is supposed to cover the rural communities remain unengaged as nursing \& midwifery services are egregiously ceded to the CHEWs who are not 


$$
\text { RN, E., and RN, G. N. }
$$

prepared educationally, ethically, or professionally to render nursing \& midwifery services or be accountable for such. Thus, unemployed Nurses \& Midwives that have been dislodged from the PHC system where they are supposed to serve and help improve the health indices of the country readily fall into the prying eyes of exploitative private hospitals in urban areas and the health system of other countries that are looking for nursing manpower to make up their deficits. Despite migration to the urban area and other countries, at least $41 \%$ of Nigerian Nurses \& Midwives produced in a session still roam about without a job.

\section{CONCLUSION}

Giving the opportunity $95 \%$ of unemployed Nurses \& Midwives are willing to work in rural community settings. At least $41 \%$ of the possible numbers of Nurses \& Midwives that can be licensed by the N\&MCN in a session are unemployed. The unemployed nurses can bridge the nursing \& midwifery manpower needs in the Primary Healthcare (PHC) system should the NPHCDA engage their services with commensurate or higher payment to what their employed counterparts receive in the Federal Government-owned hospitals and establishments. It was erroneous for the N\&MCN to blame the crass failure of the Nigeria PHC system to meet its mandate to the Nigerian people on the shortage of Nurses \& Midwives or their migration to urban areas or other countries. There is no current shortage of Nurses that necessitates the lowering of the existing standard of nursing education. Despite the said migration of Nurses to urban areas and other countries, at least $41 \%$ of Nurses \& Midwives produced in a session remain unemployed and $95 \%$ of them are willing to work in rural community settings. Nurses \& Midwives are not responsible for the design, implementation, and delivery of healthcare services at the PHC level in the community settings and therefore are not culpable for the deplorable condition and abysmal performance of the Nigerian PHC System.

\section{RECOMMENDATIONS}

1) NPHCDA should create a department of nursing \& midwifery services to oversee and handle issues of nursing \& midwifery services rather than outsourcing nursing \& midwifery services to the CHEWs as it has perennially done and currently does.

2) NPHCDA should start recruiting Nurses \& Midwives to carryout nursing \& midwifery services for which they were educated, trained, and licensed rather than outsourcing these services to the CHEWs.

3) The NPHCDA should spend a greater part of its yearly budgetary allocation on upgrading the Primary Healthcare facilities to at least the minimally acceptable global standard.

4) Nurses \& Midwives working in the rural community settings in the PHC system should receive an equal or higher remuneration than their counterparts working in Federal Government-owned establishments and hospitals.

5) The Nursing \& Midwifery Council of Nigeria (N\&MCN) should engage the NPHCDC to create a Department of Nursing Services for Nurses \& Midwives and to start employing them to render nursing \& midwifery services for the PHC system in the community settings.

6) The N\&MCN should retract the circular (Ref No. N\&MCN/SG/RO/CIR/24/VOL.4/152 dated March 3, 2020) that erroneously blamed the failure of the PHC system to make the desired impact in the Nigerian health system on the migration of Nigerian Nurses to urban areas and other countries rather than on the real cause which is the deliberate perennial war of attrition on Nurses \& Midwives by the NPHCDA that has ended up ostracizing them from the system and replacing them with the CHEWs.

7) The N\&MCN should create clinical licensure for Nurse Practitioners in the Community Health Nursing specialty at MSc \& Ph.D. levels that will equip and empower post-baccalaureate prepared Community Health Nurses to independently diagnose and treat common ailments suffered in the communities and coordinate the care of patients in the community settings as done by Nurse Practitioners in developed climes such as the United States and Canada.

8) UGONSA should engage with and submit the compiled list of the unemployed Nurses \& Midwives to the Federal Ministry of Health (FMOH), the National Assembly, the National Association of Nigerian Nurses \& Midwives (NANNM) and the N\&MCN for robust and comprehensive engagement of all stakeholders and the NPHCDA to absorb the unemployed Nurses \& Midwives in the PHC system to work in the community 
settings in line with the extant schemes of service for Nurses \& Midwives and pay them similar or higher salaries and allowances payable to Nurses \& Midwives in Federal Government-owned hospitals and establishments.

This article should be cited as follow:

\{University Graduates of Nursing Science Association [UGONSA]. (2020). Nigerian Nurses and Midwives Unemployment Survey. Position paper/Survey Diary 3\}.

\section{LIMITATIONS}

1) The findings were based on the fact that the N\&MCN grants 50 slots to each school per session and thus the possible number of graduands per session being when each school presents 50 candidates for the council exams and all the candidates presented passed the exams (100\% pass rate). This rate was adopted in order not to overestimate the unemployment rate of nurses and midwives in relation to the number of nursing \& midwifery schools.

2) The number compiled and computed was the number of unemployed Nurses \& Midwives that willingly responded online to the survey within a month (March 7 to April 8, 2020). Those that were not online during this period and even those that were online but chose not to respond to the survey were unaccounted for. Therefore the figures contained in the findings of this study may be far less than the actual number of unemployed Nurses \& Midwives in Nigeria at the time of the survey.

\section{SOURCES OF FUNDING}

None.

\section{CONFLICT OF INTEREST}

None.

\section{ACKNOWLEDGMENT}

None.

\section{REFERENCES}

[1] Abimbola, S., Okoli, U., Olubajo, O., Abdullahi, M.J., \& Pate, M.A. (2012). The Midwives Service Scheme in Nigeria. PLoS Med, 9(5): e1001211

[2] CIA World Factbook. (2018). Nigeria Maternal Mortality Rate. Index Mundi. Retrieved 26/03/20 from http://www.indexmundi.com/nigeria/maternal_mortality_rate.html.

[3] Global Health Workforce Alliance. (2017). Nigeria Midwives Service Scheme. Retrieved online 06/04/2020 from https://www.who.int/workforcealliance/forum/2011/hrhawardscs26/en/

[4] Ifijeh, M. (2016). Reducing Maternal, Child Mortality in Nigeria. Thisday March 24

[5] National Population Commission, ICF Macro (2009). Nigeria Demographic and Health Survey 2008.

[6] Abuja, Nigeria: National Population Commission and ICF Macro.2009. Google Scholar

[7] Nursing \& Midwifery Council of Nigeria [N\&MCN]. (2020a). Introduction of Community Nursing Programme as a Modalities for Strengthening Nursing Human Resources at the Primary

[8] Healthcare Level and Reduction of Maternal and Infant Mortality in Nigeria. Circular Ref No: N\&MCN/SG/RO/CIR/24/VOL.4/152, dated March 3

[9] Nursing \& Midwifery Council of Nigeria [N\&MCN]. (2020b). Approved Schools. Available online, http://nmcn.gov.ng/apschool.html. Retrieved 26/3/2020

[10] Odetola, T.D. (2015). Health care utilization among rural women of child-bearing age: a Nigerian experience. The Pan African Medical Journal. 2015; 20:151. doi:10.11604/pamj.2015.20.151.5845.

[11] Odogwu, G. (2018). Assessing SDGs implementation in Nigeria. Punch Newspaper. Available: 
https://punchng.com/assessing-sdgs-implementation-in-nigeria/

[12] Okeke, E.N., and Setodji, C.M. (2018). About the Nigerian Midwives Service Scheme (MSS). RAND Center for Causal Inference. Available online https://www.rand.org/well-being/social-and- behavioral policy/projects/born/mss.html

[13] Ononokpono, D.N., and Odimegwu, C.O. (2014). Determinants of maternal health care utilization in Nigeria: a multilevel approach. The Pan African Medical Journal, 17, (Supp 1):2. doi: 10.11604/pamj.supp.2014.17.1.3596

[14] Raufu, A. (2003). Olikoye Ransome-Kuti. British Medical Journal (BMJ), 326,(7403): 1400.

[15] UNICEF (2015). Nigeria Maternal and Child mortality in 2015. Geneva. UNICEF global databases 2015, based on MICS, DHS, and other nationally representative sources. Retrieved 27/03/20 http://data.unicef.org/.

[16] United Nations Population Fund [UNFPA]. 2014. Setting standards for emergency obstetric and newborn care. Retrieved 08/04/20 from http://www.unfpa.org/resources/setting-standards-emergency- obstetric-andnewborn-care

[17] World Health Organization [WHO] (2018). Essential obstetric care. WHO news > Fact Sheets.

[18] Retrieved online 25/03/20 from http://www.who.int/mediacentre/factsheets/fs245/en/. 